\title{
Selenium status in patients with liver cirrhosis and alcoholism
}

\author{
BY U. JOHANSSON ${ }^{1}$, F. JOHNSSON ${ }^{2}$, B. JOELSSON ${ }^{2}$, M. BERGLUND ${ }^{3}$ \\ AND B. ÅKESSON ${ }^{1 *}$ \\ Departments of ${ }^{1}$ Clinical Chemistry, ${ }^{2}$ Surgery and ${ }^{3}$ Psychiatry, University Hospital, \\ $S-22185$ Lund, Sweden
}

(Received 1 October 1984 - Accepted 26 September 1985)

\begin{abstract}
1. Selenium status and blood levels of other nutrients related to lipid peroxidation were studied in patients with advanced alcoholic liver cirrhosis, in male alcoholics who had been abstinent for at least 1 month and in healthy control subjects.

2. Plasma Se was decreased in alcoholic cirrhosis but not among alcoholics in abstinence. Platelet glutathione peroxidase (EC 1.11.1.9; GSH-Px) activity was decreased in cirrhotic patients, whereas GSH-Px in blood and plasma was the same as in controls for both groups of patients.

3. Plasma retinol and plasma $\alpha$-tocopherol were decreased in alcoholic cirrhosis, whereas plasma ascorbic acid was the same in all groups.

4. The decreases in platelet GSH-Px, plasma Se and $\alpha$-tocopherol indicate a deranged antioxidant defence in patients with advanced alcoholic cirrhosis, but the levels of these and other nutrients were generally not correlated to common clinical chemical indicators of liver disease.
\end{abstract}

In clinical practice liver damage due to ethanol is common, and several mechanisms for the action of ethanol have been advanced (Comporti, 1978; Reynolds \& Moslen, 1980; Van Waes \& Lieber, 1980). Ethanol may induce peroxidative mechanisms in the liver, since acute ethanol intoxication stimulates the production of malondialdehyde (thiobarbituric-acidreactive material (TBAR)) in liver homogenates (Comporti et al. 1973). Also, Shaw et al. (1981) have shown that after chronic feeding of ethanol to animals, increased hepatic diene conjugation and decreased concentration of glutathione can occur. These processes may be influenced by antioxidants such as vitamin $\mathrm{E}$ and vitamin $\mathrm{C}$, and also the seleno-enzyme glutathione peroxidase (EC 1.11.1.9; GSH-Px) can detoxify peroxides.

Since the liver is an important storage organ for selenium and vitamin $\mathrm{E}$ and also has the highest activity of GSH-Px (Marklund et al. 1982), liver damage may induce losses of these nutrients. It is also believed that pro-oxidant and antioxidant substances should maintain a balance, and evidently the interplay between ethanol and the previously mentioned nutrients may disturb this balance. Whether liver damage in humans can be ameliorated by supplementation of single nutrients or mixtures thereof is not known.

To elucidate some of these problems we have studied nutrients related to peroxidation in patients with different degrees of liver damage. This included Se, $\alpha$-tocopherol, retinol and ascorbic acid and endogenous markers of lipid peroxidation.

\section{MATERIALS AND METHODS \\ Material}

Three groups of subjects were studied. Group 1: twenty-one patients with biopsy-proven liver cirrhosis and a history of at least one bleeding episode from endoscopically-verified bleeding oesophageal varices were studied. Percutaneous transhepatic portal vein catheterization in all patients revealed portal hypertension ( $>250 \mathrm{~mm}$ water). There were sixteen 
men and five women aged 33-76 years. All patients had alcoholic liver cirrhosis. The patients lived under good socio-economic conditions with access to adequate nutrition. No patient reported the use of vitamin or mineral supplements. Several were treated with diuretics. They were admitted to the hospital for clinical control or due to oesophageal bleeding. Overnight fasting blood samples were obtained from an antecubital vein following $4 \mathrm{~d}$ in hospital with abstinence from alcohol and regular hospital food containing $80 \mathrm{~g}$ protein/d. Group 2: this group comprised fifteen male alcoholics (age 31-61 years) with alcohol dependence, DSM-III (American Psychiatric Association, 1980), from an out-patient treatment programme, with known and collaborated abstinence for at least 1 month before the study and with no clinical or biochemical indications of liver cirrhosis. All were living under good socio-economic conditions. Group 3: the control group consisted of sixteen subjects (eight women and eight men, 29-71 years). They were visiting the hospital for minor surgery and were otherwise healthy. From all subjects blood samples were obtained after an overnight fast. The design of the study was approved by the Ethics Committee of the University of Lund.

\section{METHODS}

Blood samples were taken using heparin or EDTA as anticoagulant. Blood and plasma were analysed for GSH-Px using tert-butylhydroperoxide as substrate (Günzler et al. 1974). Se was determined by gas-liquid chromatography ( kesson \& Öckerman, 1985). Ascorbic acid was measured by spectrophotometry using $\mathrm{Fe}^{3+}$ in acidic solution and $\alpha, \alpha$-dipyridyl as reagents (Okamura, 1980).

$\alpha$-Tocopherol and retinol were extracted from serum after the addition of $\delta$-tocopherol as internal standard. They were quantified by high performance liquid chromatography on a Nucleosil C18 column $(200 \times 4.5 \mathrm{~mm})$, essentially according to De Leenheer et al. (1979). Lipid fluorescence in erythrocytes was measured with fluorometry (excitation at $360 \mathrm{~nm}$, emission at $440 \mathrm{~nm}$ ) after extraction of washed erythrocytes with propan-2-ol-chloroform $(11: 7, \mathrm{v} / \mathrm{v})$ (Rose \& Oklander, 1965). The fluorescence was related to the amount of lipid phosphorus (Simonsson et al. 1982) in the extracts and to a standard of quinine sulphate. TBAR in plasma was measured by fluorometry (Yagi, 1976).

$\alpha_{1}$-Antitrypsin, haptoglobin, immunoglobulin $\mathrm{G}$, immunoglobulin A, orosomucoid and caeruloplasmin were quantified by electroimmunoassay (Laurell, 1972). Albumin was determined by a turbidimetric method using an antialbumin antibody. Aspartate aminotransferase (EC 2.6.1.1), alanine aminotransferase $(E C 2.6 .1 .2)$, alkaline phosphatase $(E C$ 3.1.3.1) and $\gamma$-glutamyl transferase $(E C 2.3 .2 .2)$ were determined essentially as described by the Committee on Enzymes of the Scandinavian Society for Clinical Chemistry and Clinical Physiology (1974).

Blood samples $(8 \mathrm{ml})$ for platelet isolation were collected in tubes containing $1.4 \mathrm{ml}$ citric acid $(38 \mathrm{mmol} / \mathrm{l})$, sodium citrate $(75 \mathrm{mmol} / \mathrm{l})$ and glucose $(136 \mathrm{mmol} / \mathrm{l})$. Platelets were isolated by centrifugation according to Levander et al. (1983b). After isolation they were disintegrated using ultrasonication with a titanium probe. The samples were centrifuged at $65000 \mathrm{~g}_{\max }$ for $1 \mathrm{~h}$ at $4^{\circ}$, and GSH-Px was determined in the supernatant fraction as described previously. Protein was determined according to Lowry et al. (1951). The significance of differences between groups of subjects was calculated by the Mann-Whitney procedure.

\section{RESULTS}

Plasma Se was depressed in cirrhotic patients $(P<0.001)$ but was normal in alcoholics (Table 1). The latter patients and the controls fell essentially within the reference interval found previously, 0.68-1.28 $\mu \mathrm{mol} / 1$ ( $\AA$ kesson \& Öckerman, 1985). Analysis of total blood 


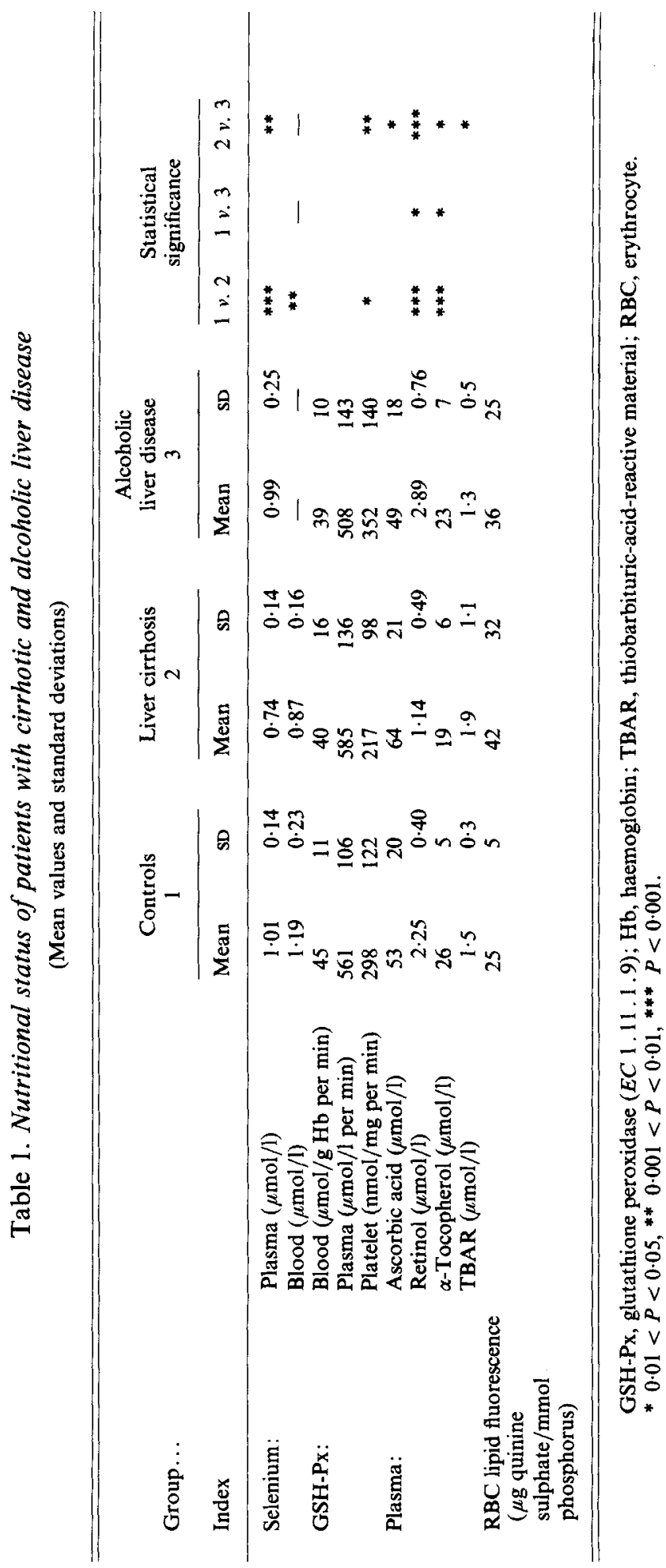




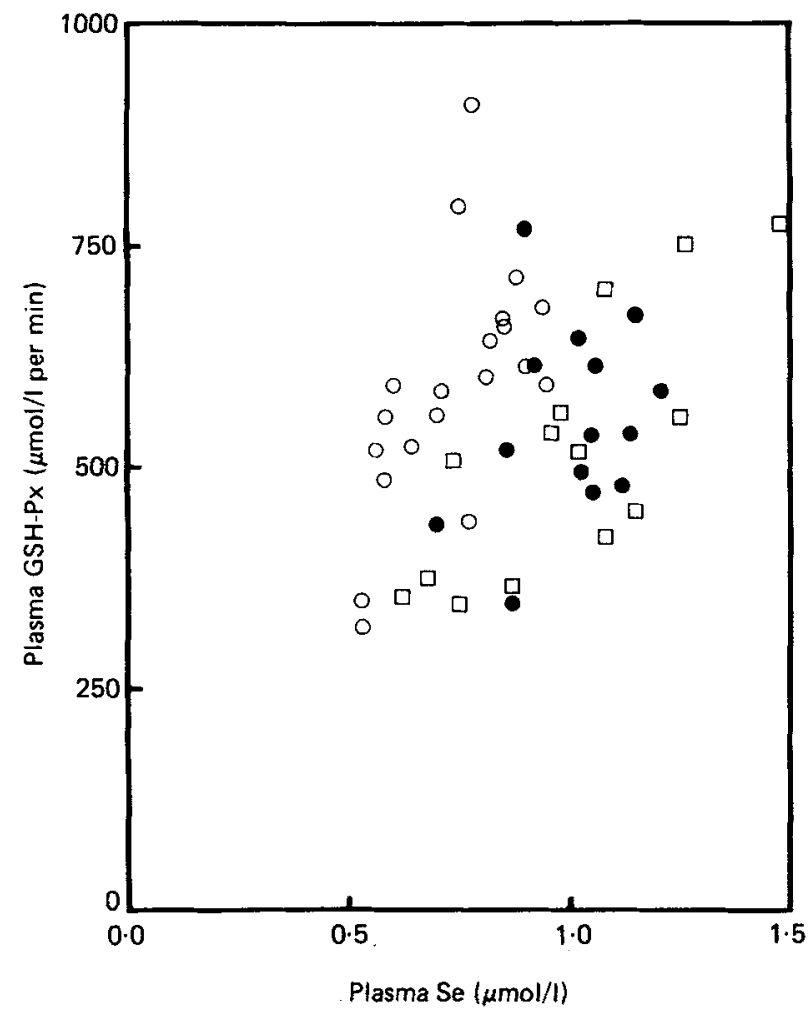

Fig. 1. Relation between plasma selenium and plasma glutathione peroxidase (EC 1.11.1.9; GSH-Px) among patients with alcoholic cirrhosis $(O)$, alcohol-induced liver disease $(\square)$ and healthy controls $(O)$. The correlation coefficient in the whole material was $0.35(P<0.01)$.

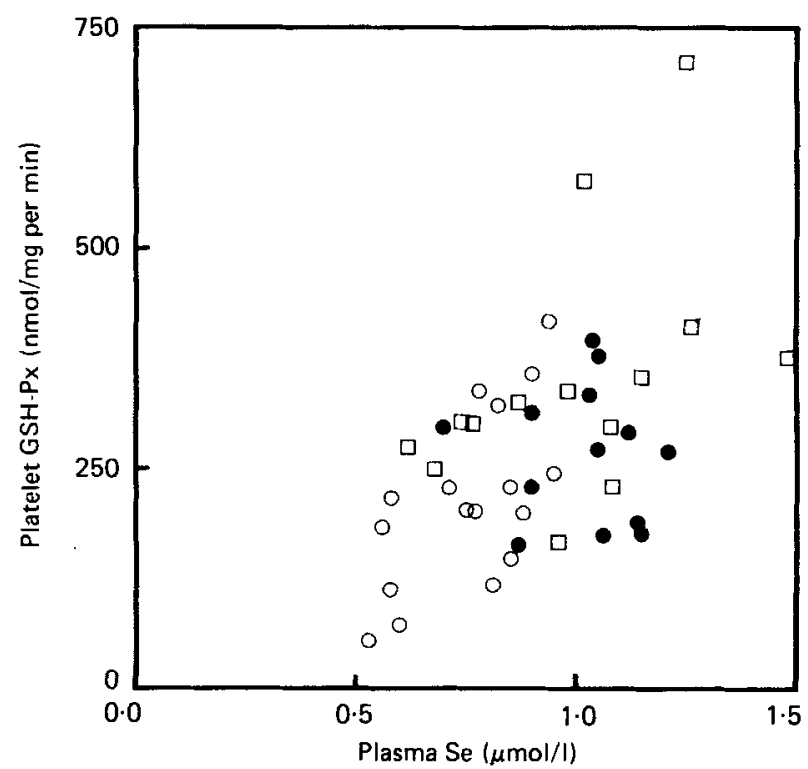

Fig. 2. Relation between plasma selenium and platelet glutathione peroxidase (EC 1.11 .1 .9; GSH-Px) among patients with alcoholic cirrhosis $(O)$, alcohol-induced liver disease $(\square)$ and healthy controls $(O)$. The correlation coefficient in the whole material was $0.51(P<0.001)$. 
Table 2. General clinical-chemical analyses among patients with cirrhosis and alcoholic liver disease

(Mean values with ranges in parentheses)

\begin{tabular}{|c|c|c|c|}
\hline Index & $\begin{array}{l}\text { Alcoholic } \\
\text { cirrhosis } \\
\left(\begin{array}{l}n \\
21)\end{array}\right.\end{array}$ & $\begin{array}{l}\text { Alcoholic } \\
\text { liver disease } \\
(n 15)\end{array}$ & $\begin{array}{c}\text { Reference } \\
\text { interval }\end{array}$ \\
\hline Bilirubin $(\mu \mathrm{mol} / \mathrm{l})$ & $47(12-326)$ & $9(6-14)$ & $3-20$ \\
\hline $\begin{array}{l}\text { Alkaline phosphatase } \\
(E C 3.1 .3 .1)(\mu \mathrm{kat} / \mathrm{l})\end{array}$ & $6.9(2 \cdot 6-34 \cdot 0)$ & $3.1(1.9-5.5)$ & $0.8-4.6$ \\
\hline $\begin{array}{l}\gamma \text {-Glutamyl transferase } \\
(E C 2.3 .2 .2)(\mu \mathrm{kat} / \mathrm{l})\end{array}$ & $3.8(0.8-13.0)$ & $0.7(0 \cdot 2-1 \cdot 7)$ & $<1.0$ \\
\hline $\begin{array}{l}\text { Aspartate aminotransferase } \\
(E C \text { 2.6.1.1) }(\mu \mathrm{kat} / 1)\end{array}$ & $0.8(0.4-1.8)$ & $0.5(0.2-0.7)$ & $<0.67$ \\
\hline $\begin{array}{l}\text { Alanine aminotransferase } \\
(E C 2.6 .1 .2)(\mu \mathrm{kat} / \mathrm{l})\end{array}$ & $0.4(0.1-1 \cdot 5)$ & $0.4(0.2-0.9)$ & $<0.67$ \\
\hline Albumin $(g / 1)$ & $36(17-45)$ & $41(37-45)$ & $40-52$ \\
\hline Immunoglobulin $\mathrm{G}(\mathrm{g} / \mathrm{l})$ & $16.6(8.9-25.0)$ & $9 \cdot 9(6 \cdot 8-15 \cdot 1)$ & $7-15$ \\
\hline Immunoglobulin A (g/l) & $4 \cdot 6(1 \cdot 3-17 \cdot 0)$ & $2 \cdot 8(1 \cdot 1-5 \cdot 3)$ & $0.5-3 \cdot 0$ \\
\hline$\alpha_{1}$-Antitrypsin (g/l) & $1.8(0.9-3.6)$ & $1.6(1 \cdot 3-2 \cdot 0)$ & $0 \cdot 9-1 \cdot 7$ \\
\hline Orosomucoid $(\mathrm{g} / 1)$ & $0.59(0.27-1.17)$ & $1.02(0.64-1.38)$ & $0.55-1.05$ \\
\hline Haptoglobin (g/l) & $0.67(0.00-1.54)$ & $1.48(0.60-2 \cdot 34)$ & $0.30-1.80$ \\
\hline Caeruloplasmin $(\mathrm{g} / \mathrm{l})$ & $0.32(0.18-0.46)$ & $0.33(0.26-0.42)$ & $0.22-0.48$ \\
\hline Blood haemoglobin $(\mathrm{g} / \mathrm{l})$ & $127(92-165)$ & $152(132-165)$ & $131-1630$ \\
\hline
\end{tabular}

kat, $1 \mathrm{~mol}$ substrate transformed/s.

Se in a limited number of patients also indicated a decreased concentration in cirrhotic patients compared with controls $(P<0.01)$.

The activity of GSH-Px in blood and plasma was the same in both groups of patients and in controls (Table 1). Platelet GSH-Px, proposed as a useful indicator of Se status, was depressed in the cirrhotic patients but was normal among alcoholics (Table 1). In the cirrhotic group, plasma Se was positively correlated to GSH-Px in plasma $(r 0.65, P<0.01)$ and in platelets $(r 0.64, P<0.01)$. The correlations in the whole material are shown in Figs. 1 and 2. Neither of these variables was correlated to blood GSH-Px, but in the cirrhotic group the activities of plasma and platelet GSH-Px covaried $(r 0.51, P<0.05)$. Plasma Se was not significantly correlated to any of the major plasma proteins measured.

Several other nutrients related to lipid peroxidation and liver damage were measured. The concentration of $\alpha$-tocopherol and retinol in plasma was significantly depressed in the cirrhotic patients (Table 1). Plasma ascorbic acid was the same among the three groups. Another two measurements, plasma TBAR and lipid-soluble fluorescent products in erythrocytes, which have been proposed to reflect lipid peroxidation, were similar in all groups. They were not correlated to variables of Se status among cirrhotics.

Serum bilirubin and serum alkaline phosphatase were increased in half the cirrhotic patients, whereas $\gamma$-glutamyl transferase was elevated in the majority of cirrhotic patients and also in some alcoholic patients (Table 2). Aspartate aminotransferase was elevated in half the cirrhotic patients but alanine aminotransferase activity only in a few patients. Several cirrhotic patients had anaemia. Among plasma proteins, albumin, orosomucoid and haptoglobin exhibited lower concentrations in patients with liver cirrhosis, whereas immunoglobulins and $\alpha_{1}$-antitrypsin were often elevated. 


\section{DISCUSSION}

The present study demonstrates several derangements in Se status of patients with liver cirrhosis. A decrease in plasma Se has previously been found by Aaseth et al. (1982) and Välimäki et al. (1983). It may be due to a low Se intake, deranged Se absorption or metabolism, or it may be secondary to the changes in plasma proteins since much of plasma Se is protein-bound. However, there was no correlation of Se to the major plasma proteins in the present study, not even to albumin as previously found (Aaseth et al. 1982; Välimäki et al. 1983). Dutta et al. (1983) observed that plasma Se increased during alcohol detoxification at a hospital and concluded that a previous deficient $\mathrm{Se}$ intake was the main cause of the low plasma Se.

Blood and plasma GSH-Px were unchanged in liver cirrhosis, suggesting that the decrease in plasma Se affects other seleno-proteins. Most of the Se in plasma is located in proteins other than GSH-Px (Motsenbecker \& Tappel, 1982; Beilstein \& Whanger, 1983).

The platelet activity of GSH-Px has been proposed as a sensitive index of Se status (Levander et al. 1983a,b). Our study is the first to demonstrate a decrease in this enzyme activity in liver cirrhosis, which together with the decrease in plasma Se indicates a deranged Se status in cirrhotic patients but not in alcoholics. The functional significance of the decrease in platelet GSH-Px is hard to assess. The enzyme catalyses the reduction of 12-hydroperoxyeicosatetraenoic acid to 12-hydroxyeicosatetraenoic acid (Bryant et al. 1983), and it may also protect the platelets from peroxides. Interestingly, the enzyme activity is depressed also in patients with myocardial infarction (Wang et al. 1981).

Among our patients no change in plasma ascorbic acid was observed. This is in contrast to previous findings of low ascorbic acid concentrations both in plasma and in leucocytes in cirrhotic patients (Beattie \& Sherlock, 1976; Bonjour , 1979; Devgun et al. 1981). The decrease in plasma retinol and plasma $\alpha$-tocopherol in cirrhotic patients agrees with several previous studies (Bonjour, $1981 a, b$ ). The mechanism behind the decrease may be insufficient intake, low absorption, low concentration of vitamin-binding proteins or increased degradation of the vitamins due to increased lipid peroxidation.

In conclusion, the present study indicates that patients with liver cirrhosis may have a deranged antioxidant defence since plasma Se, platelet GSH-Px and plasma $\alpha$-tocopherol are depressed. The relations of these nutrients to the clinical course of disease and the possible effects of dietary changes or supplementation with the nutrients mentioned are unknown at present.

It is noteworthy that the alcoholics without signs of cirrhosis did not show the biochemical changes found in the cirrhotic group. The alcoholics were chosen from an out-patient treatment programme with known and collaborated abstinence. Thus the sample certainly represented alcoholics but their biochemical indices were not influenced by a present alcohol consumption or a typical alcoholic life-style. Our findings for the cirrhotic group could not be explained by the alcoholism itself, therefore, but instead by the concomitant liver disorder.

The authors thank Dr S. Bengmark, Head of the Department of Surgery, for his support, and Ms B. Martensson and Ms I. Nilsson for skilful assistance. The study was supported by grants from the Swedish Medical Research Council (project 3968) and the Swedish Nutrition Foundation. 
American Psychiatric Association (1980). Diagnostic and Statistical Manual of Mental Disorders, 3rd ed. Washington DC: APA.

Beattie, A. D. \& Sherlock, S. (1976). Gut $17571-575$.

Beilstein, M. A. \& Whanger, P. D. (1983). Journal of Nutrition 113, 2138-2146.

Bonjour, J. P. (1979). International Journal for Vitamin and Nutrition Research 49, 434441.

Bonjour, J. P. (1981 a). International Journal for Vitamin and Nutrition Research 51, 307-318.

Bonjour, J. P. (1981 b). International Journal for Vitamin and Nutrition Research 51, 166-177.

Bryant, R. W., Simon, T. C. \& Bailey, J. M. (1983). Journal of Biological Chemistry 257, 14937-14943.

Committee on Enzymes of the Scandinavian Society for Clinical Chemistry and Clinical Physiology (1974). Scandinavian Journal of Clinical and Laboratory Investigation 33, 291-306.

Comporti, M. (1978). In Biochemical Mechanisms of Liver Injury, pp. 469-516 [T. F. Slater, editor]. London: Academic Press.

Comporti, M., Benedetti, A. \& Chieli, E. (1973). Lipids 8, 498-502.

De Leenheer, A. P., De Bevere, V. O. R. C., De Ruyter, M. G. M. \& Claeys, A. E. (1979) Journal of Chromatography $162,408-413$.

Devgun, M. S., Fiabane., A., Paterson, C. R., Zarembski, P. \& Guthrie, A. (1981). British Journal of Nutrition 45, 469-473.

Dutta, S. K., Miller, P. A., Greenberg, L. B. \& Levander, O. A. (1983). American Journal of Clinical Nutrition 38, 713-718.

Günzler, W. A., Kremers, H. \& Flohé, L. (1974). Zeitschrift für Klinische Chemie und Klinische Biochemie 12, $444-448$

Laurell, C.-B. (1972). Scandinavian Journal of Clinical and Laboratory Investigation 29, Suppl. 124, $21-37$.

Levander, O. A., Alfthan, G., Arvilommi, H., Gref, C. G., Huttunen, J. K., Kataja, M., Koivistoinen, P. \& Pikkarainen, J. (1983 a). American Journal of Clinical Nutrition 37, 887-897.

Levander, O. A., DeLoach, D. P., Morris, V. C. \& Moser, P. B. (1983b). Journal of Nutrition 113, 55-63.

Lowry, O. H., Rosebrough, N. J., Farr, A. L. \& Randall, R. J. (1951). Journal of Biological Chemistry 193, 265-275.

Marklund, S. L., Westman, N. G., Lundgren, E. \& Roos, G. (1982). Cancer Research 42, 1955-1961.

Motsenbecker, M. A. \& Tappel, A. L. (1982). Biochimica et Biophysica Acta 704, 253-260.

Okamura, M. (1980). Clinica Chimica Acta 103, 259-268.

Reynolds, E. S. \& Moslen, M. T. (1980). In Free Radicals in Biology vol. IV, pp. 49-94 [W. A. Pryor, editor]. London: Academic Press.

Rose, H. G. \& Oklander, M. (1965). Journal of Lipid Research 6, 428-431.

Shaw, S., Jayatilleke, E., Ross, W. A., Gordon, E. R. \& Lieber, C. S. (1981). Journal of Laboratory and Clinical Medicine 98, 417-424.

Simonsson, P., Nilsson, A., \& Åkesson, B. (1982). American Journal of Clinical Nutrition 35, 36-41.

Välimäki. M. J., Harju, K. J. \& Ylikahri, R. H. (1983). Clinica Chimica Acta 130, 291-296.

Van Waes, L. \& Lieber, C. S. (1980). In Toxic Injury of the Liver, pp. 629-653 [E. Farber and M. M. Fisher, editors]. New York: Marcel Dekker.

Wang, Y. X., Böcker, K., Reuter, H., Kiem, J., Kasperek, K., Iyengar, G. V., Loogen, F., Gross, R. \& Feinendegen, L. E. (1981). Klinische Wochenschrift 591, 817-818.

Yagi, K. (1976). Biochemical Medicine 15, 212-216. 